\title{
The Association of Leprosy and Spinal Psammomatous Meningioma: A Case Report
}

\author{
Ibrahim Burak Atci ${ }^{\mathrm{a}, \mathrm{c}}$, Serdal Albayrak ${ }^{\mathrm{a}}$, Necati Ucler ${ }^{\mathrm{b}}$, Emre Durdag $^{\mathrm{a}}$, Omer Ayden $^{\mathrm{a}}$
}

\begin{abstract}
Leprosy or Hansen's disease (HS) caused by Mycobacterium leprae may involve all organ systems, especially skin and nervous system, and is an contagious disease. The responsible organism is M. leprae which is an acid-fast staining bacilli and similar to M. tuberculosis. Spinal masses are rarely seen tumoral lesions. Intradural spinal masses are generally extradural located meningiomas, nerve-sheath tumors and metastasis. A 68-year-old female patient followed up by a local leprosy center was admitted for new onset lower extremity motor deficits and urinary incontinence. Cervical MRI showed the mass in size of $3 \times 1.5 \mathrm{~cm}$. The case was operated under general anesthesia and the lesion was located in the intradural extramedullary space with smooth border and removed totally. The pathologic result was reported as psammomatous meningioma. The purpose of this study was to present the improvement of paraparesis in the case with rarely seen lepromatous type leprosy and a spinal mass which was histologically psammomatous meningioma after emergent surgical intervention.
\end{abstract}

Keywords: Leprosy; Spinal tumor; Psammomatous menengioma

\section{Introduction}

Leprosy or Hansen's disease (HS) caused by Mycobacterium

Manuscript accepted for publication October 2, 2013

${ }^{a}$ Department of Neurosurgery, Elazig Training Research Hospital, Hospital Street Rizaiye Road, 23100 Elazig, Turkey

${ }^{\mathrm{b}}$ Department of Neurosurgery, Adiyaman University, Education and Research Hospital, 02200 Adiyaman, Turkey

${ }^{\mathrm{c}}$ Corresponding author: Ibrahim Burak Atci, Department of

Neurosurgery, Elazig Training and Research Hospital, Elazig Training and Research Hospital, Hospital Street Rizaiye Road, 23100 Elazig,

Turkey. Email: drburakatci@hotmail.com

doi: http://dx.doi.org/10.14740/jmc1389w leprae may involve all organ systems, especially skin and nervous system, and is an contagious disease. The responsible organism is $M$. leprae which is an acid-fast staining bacilli and similar to M. tuberculosis. The bacteria multiply very slowly, and its incubation period is approximately 5 years. Sometimes its symptoms may seen in 25 years. Lepromatous type leprosy, tuberculoid type leprosy, borderline type leprosy and indeterminate type leprosy are four types of leprosy [1]. When we screened the literature, there was no association with leprosy and the common tumors in the literature $[2,3]$.

Spinal masses are rarely seen tumoral lesions. However, these lesions are the main cause of morbidity, such as extremity dysfunction, urinary and stool incontinance and may lead to mortality associated with these morbidities. Intradural spinal masses are generally extradural located meningiomas, nerve-sheath tumors and metastasis [1]. Meningiomas are mostly seen in older age groups between 5 th and 6th decades. Seventy percent of cases with meningioma is female and these tumors are generally located in the thoracal region [1]. Spinal meningiomas are mainly in meningothelial type (29-59\%) or psammomatous type (21-57\%) [4, 5].

The purpose of this study was to present the improvement of paraparesis in the case with rarely seen lepromatous type leprosy and a spinal mass which was histologically psammomatous meningioma after emergent surgical intervention.

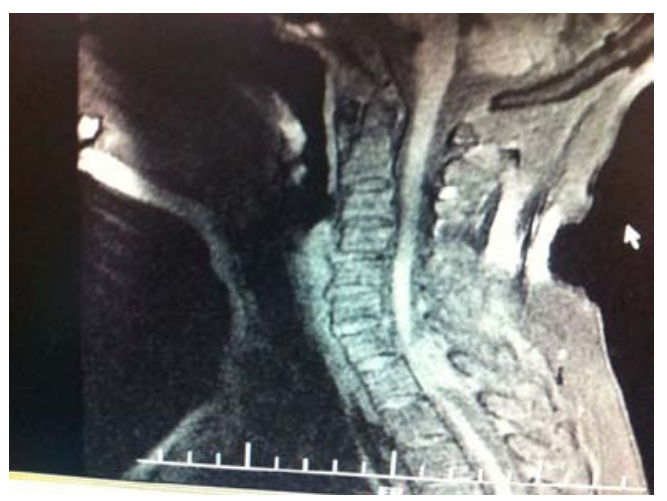

Figure 1. Cervical T-1 weighted MRI. 


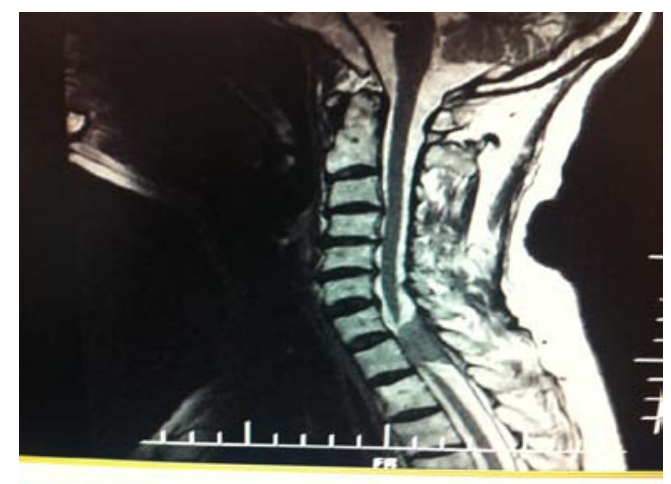

Figure 2. Cervical T-2 weighted sagittal MRI .

\section{Case Report}

A 68-year-old female patient followed up by a local leprosy center was admitted for new onset lower extremity motor deficits and urinary incontinence. The patient was suffering from lepromatous type leprosy for 25 years and had advanced lower motor deficits and urinary incontinence. The patient was screened by cranial, cervical and thoracal magnetic resonance imaging (MRI). Cervical MRI showed the mass in size of $3 \times 1.5 \mathrm{~cm}$ which was peripherally contrasted hyperintense at T-1 weighted MRI sequences (Fig. 1) and hyporintense at T-2 weighted MRI sequences (Fig. 2-4). The case was operated under general anesthesia and the lesion was located in the intradural extramedullary space with smooth border and removed totally (Fig. 5, 6). The pathologic result was reported as psammomatous meningioma (Fig. $7,8)$. The patient's paresis improved after emergent surgical intervention.

\section{Discussion}

Meningiomas located at spine account for $14-25 \%$ of all spinal tumors $[6,7]$. The frequency of meningiomas located

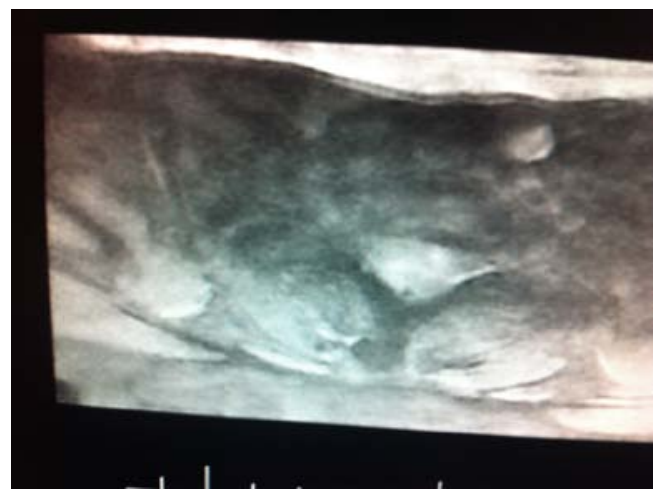

Figure 4. Cervical T-2 weighted axial MRI.

at spine varies between 1.2 and $12 \%$ [8]. These pathologies are commonly located in the thoracal region $[9,10]$. Meningiomas are seen 1.5-3 times more common in females than males $[9,10]$. Although meningiomas may be seen in all age groups, generelly their frequency increases with age [11].

Spinal meningiomas may show various clinical sypmtoms. Its main sypmtoms are pain, sensory deficits, motor deficits, sphincter deficiency, reflex defects (hyperreflexia and pathologic reflexes) and spasity. Because they are generally slow growing tumors, their sypmtoms emerge slowly rather than acute onset [12].

There is a special classification for the evaluation of patients with spinal meningiomas. McCormick classification or other functional neurologic classifications have been used for spinal meningiomas $[6,13]$.

The best radiologic modality for spinal meningiomas is spinal MRI. They are seen as isointense at T-1 weighted and T-2 weighted MRI sequences. Sometimes they may be seen hypointense at T-1 weighted MRI and hyperintense at T-2 weighted MRI. These masses are homogeneously contrasted in MRI.

The timing of surgical treatment varies according to patient's clinical picture as emergent or elective intervention. Meningiomas' surgery is planned according to tumor local-

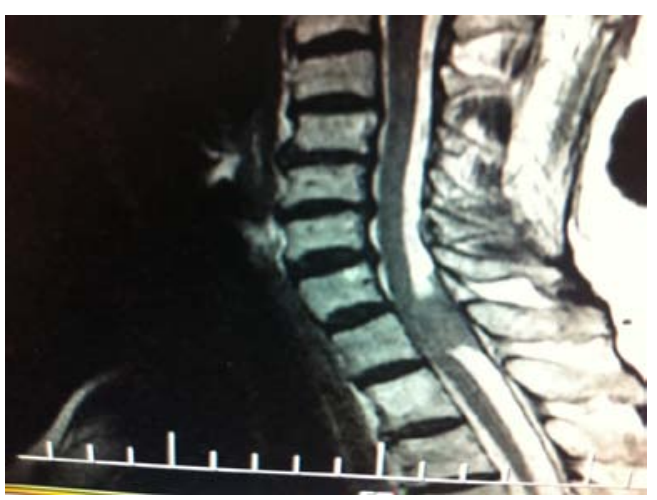

Figure 3. Cervical T-2 weighted sagittal MRI sequences.

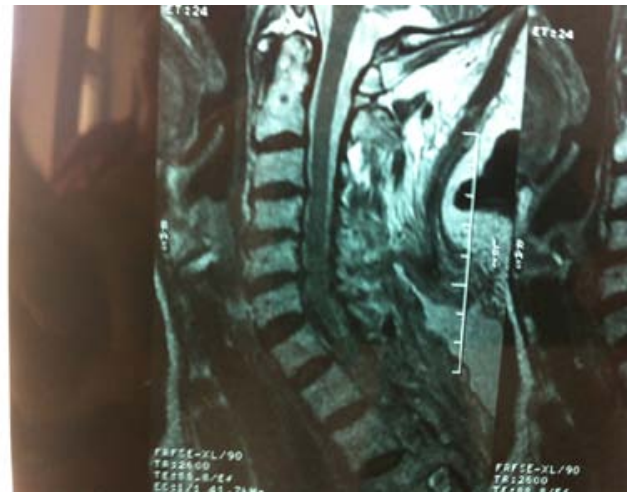

Figure 5. Postoperative T1 cervical sagittal MRI. 


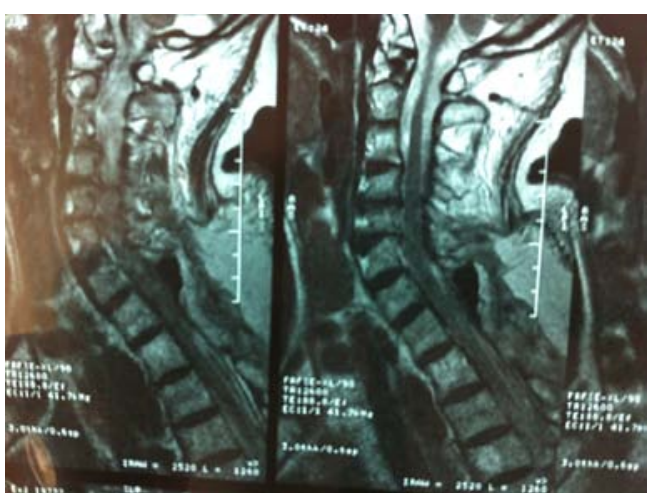

Figure 6. Postoperative T2 cervical sagittal MRI.

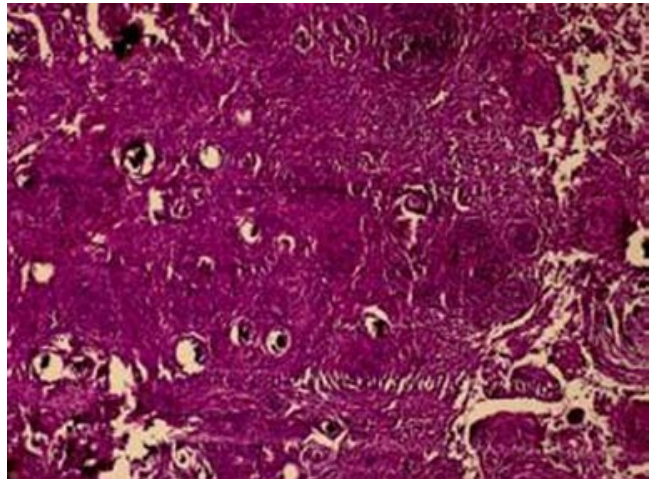

Figure 8. Pathologic result. ization and size, and generally tumors localized in posterior or postero-lateral part of the spinal canal can be removed with posterior approach by hemilaminectomy, laminectomy or costatransversectomy. Simpson's intracranial meningiomas classification can be used for surgical resection classification of the spinal meningiomas [14].

It was reported that the surgical resection of psammomatous type among the spinal meningiomas was more difficult and neurologic deterioration after the surgery could be present [14].

When looked at retrospective series in literature, its recurrence rate varies between 1 and $15 \%[6,10]$. The recurrence is seen generally in high grade meningiomas (grade III-IV). It was reported that the need of re-operation was $22.5 \%$ in younger age groups and $10 \%$ in older age groups for recurrent spinal meningiomas after total or partial removal of meningiomas [3]. When 80 patients with spinal meningiomas treated surgically are histopathologically examined, it was reported that $87.5 \%$ in grade I (meningothelial $(57.4 \%)$, psammomatous $(8.8 \%)$, microcystic $(1.3 \%)$, chordoid (1.3\%), fibrous (2.5\%)), 7.5\% in grade II (atypic), $2.5 \%$ in grade III (malign) and $2.5 \%$ in grade IV (meningiosarcoma) $[12,15]$.

Leprosy is a chronic infection caused by the leprosy

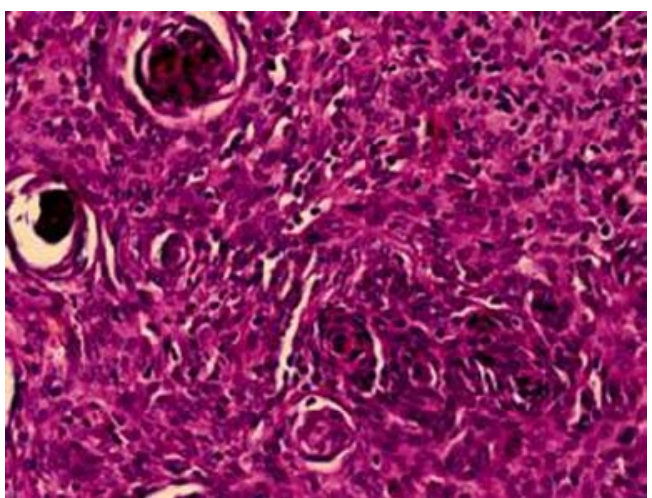

Figure 7. Pathologic result. bacilli firstly found by Armauer Hansen in 1876. Leprosy, known as HS, primarily affects peripheric nerves and secondarily affects skin and other organs and it is progressive disease caused by $M$. leprae and female/male ratio is about 1:2. Leprosy is mainly a peripheric neuropathy. When the leprosy bacilli invades the body, and then its target is to localize in Schwann cells of the peripheric nerves and its frequency is about $1 / 10,000$ in these cells $[2,3]$.

The association of leprosy and meningioma has not been reported in literature. In our study, we aimed to present that the development of paraparesia due to psammomatous meningioma in the case with rarely seen lepromatous type leprosy improved after the emergent surgical treatment.

\section{References}

1. Van Goethem JW, van den Hauwe L, Ozsarlak O, De Schepper AM, Parizel PM. Spinal tumors. Eur J Radiol. 2004;50(2):159-176.

2. Ferri. Ferri's Clinical Advisor. 1st ed. 2013.

3. Bope and Kellerman. Conn's Current Therapy. 1st ed. 2012.

4. Levy WJ, Jr., Bay J, Dohn D. Spinal cord meningioma. J Neurosurg. 1982;57(6):804-812.

5. Roux FX, Nataf F, Pinaudeau M, Borne G, Devaux B, Meder JF. Intraspinal meningiomas: review of 54 cases with discussion of poor prognosis factors and modern therapeutic management. Surg Neurol. 1996;46(5):458463; discussion 463-454.

6. Stanton CA, Challa VR. Meningiomas: pathology. In: Wilkins RH, Rengachary SS, eds. Neurosurgery: Second ed. New York: McGraw-Hill Publisher. 1996:843.

7. Wen-qing H, Shi-ju Z, Qing-sheng T, Jian-qing H, Yuxia L, Qing-zhong X, Zi-jun L, et al. Statistical analysis of central nervous system tumors in China. J Neurosurg. 1982;56(4):555-564.

8. Greenberg MS. Handbook of Neurosurgery. Third ed. Florida: Greenberg Graphics. 1994;620-623. 
9. Torres LF, Madalozzo LE, Werner B, de Noronha L, Jacob GV, Medeiros BC, Vialle EN. [Meningiomas. Epidemiological and anatomopathological study of 340 cases]. Arq Neuropsiquiatr. 1996;54(4):549-556.

10. Rohringer M, Sutherland GR, Louw DF, Sima AA. Incidence and clinicopathological features of meningioma. J Neurosurg. 1989;71(5 Pt 1):665-672.

11. Kuratsu J, Takeshima H, Ushio Y. Trends in the incidence of primary intracranial tumors in Kumamoto, Japan. Int J Clin Oncol. 2001;6(4):183-191.

12. Das A, Tang WY, Smith DR. Meningiomas in Singapore: demographic and biological characteristics. J Neu- rooncol. 2000;47(2):153-160.

13. Yurt A, Kocanogulları O, Cakir Y, Bardakci S ve ark. Spinal meningiomlar. Ege Tip Derg. 1999;38(3):145148.

14. Cordera S, Bottacchi E, D’Alessandro G, Machado D, De Gonda F, Corso G. Epidemiology of primary intracranial tumours in NW Italy, a population based study: stable incidence in the last two decades. J Neurol. 2002;249(3):281-284.

15. Gezen F, Kahraman S, Canakci Z, Beduk A. Review of 36 cases of spinal cord meningioma. Spine (Phila $\mathrm{Pa}$ 1976). 2000;25(6):727-731. 